\title{
Interleukin-1 and estrogen protect against disseminating dentoalveolar infections
}

\author{
Hesham Youssef $^{\#}$ and Philip Stashenko \\ Dentoalveolar bacterial infections cause localized tissue and bone destruction, but usually remain well-localized within teeth in \\ immunocompetent hosts. However, in certain cases these infections may invade head and neck tissues, resulting in orofacial \\ abscesses, cellulitis and sepsis, with resultant high morbidity and even mortality. In the present studies, we developed a novel \\ model of spreading dentoalveolar infections in mice by treatment with neutralizing antibodies against both interleukin-1 $\alpha$ (IL-1 $\alpha$ ) \\ and IL-1ß. Surprisingly male but not female mice given anti-IL-1 antibodies developed orofacial abscesses, weight loss, \\ splenomegaly and sepsis. Female mice developed abscesses and sepsis comparable to males following ovariectomy (OVX), which \\ was reversed by estrogen supplementation. Anti-IL-1 blockade inhibited IL-12, interferon $\gamma$ (IFN $\gamma$ ) and IL-6 but not IL-10 \\ expression in infrabony lesions, suggestive of a local anti-inflammatory response. There was greater infiltration of neutrophils and \\ other inflammatory cells into lesions in anti-IL-1-treated animals; however, blood leukocytes had reduced bacterial phagocytic \\ and killing activity ex vivo. Estrogen directly stimulated IL-1 production by macrophages, suggesting that the resistance of \\ females to disseminating dentoalveolar infections may be due to their heightened pro-inflammatory responses following bacterial \\ challenge, leading to enhanced localization of these infections. \\ International Journal of Oral Science (2017) 9, 16-23; doi:10.1038/ijos.2016.61; published online 30 March 2017
}

Keywords: cytokines; dentoalveolar; disseminating infections; estrogen; neutrophils

\section{INTRODUCTION}

Dentoalveolar abscesses and disseminating infections of endodontic origin occur as sequellae of bacterial invasion of the dental pulp. Dentoalveolar abscesses result from the large-scale egress of bacteria from the root canal system into surrounding tissues, which evade ingestion and destruction by phagocytic leukocytes and other local immune mechanisms. If not promptly and effectively treated, these infections can rapidly spread by dissection along fascial planes, and result in cellulitis, sinusitis, deep space infections of the head and neck, intracranial abscesses and frank sepsis, resulting in significant morbidity and even mortality. ${ }^{1-2}$

The immune responses that localize these infections and prevent their dissemination are not fully understood. In previous studies, we showed that B-cell- but not T-cell-deficient mice were susceptible to abscess formation and sepsis, and that passively transferred antibody, primarily IgG, against infecting bacteria was protective. ${ }^{3-4}$ Mice doubly deficient in P- and E-selectin and reduced phagocyte migration, had decreased ability to slow the progress of dentoalveolar infections. ${ }^{5}$ Conversely, animals treated with the immunomodulator poly-(1-6)beta-D-glucopyranosyl-(1-3)-beta-D-glucopyranose (PGG)-glucan, which enhances neutrophil production and priming, had greater infection resistance. ${ }^{6}$ Taken together these data indicate that antibody-mediated bacterial opsonization, combined with efficient phagocytosis and killing of bacteria by neutrophils are critical elements for protection.

In the present study, we further investigated the role of phagocytic leukocyte priming in the context of sex specificity, using a novel mouse model of disseminating dentoalveolar infections.

\section{MATERIALS AND METHODS}

Mice

Eight-week-old C57Bl/6 male and female mice were purchased from Jackson Laboratory, Bar Harbor, ME, USA. Ovariectomized (OVX) and sham OVX 9-week-old C57Bl/6 female mice were obtained from Jackson Laboratory 2 weeks after surgery. Animals were maintained in a conventional environment in the AAALAC accredited Forsyth Institute Animal Facility, according to the guidelines of the Institutional Animal Care and Use Committee (IACUC) under protocol \#14009. All procedures conformed to the National Institutes of Health (NIH) guide for the care and use of laboratory animals (NIH publication no. 8023, 2010).

\section{Dentoalveolar infections}

For infection induction, mice were mounted on a jaw retraction board and anesthetized with ketamine HCI $\left(62.5 \mathrm{mg} \cdot \mathrm{kg}^{-1}\right)$ and xylazine $\left(12.5 \mathrm{mg} \cdot \mathrm{kg}^{-1}\right)$ in sterile phosphate-buffered saline by intraperitoneal 
injection. Both lower first molar dental pulps were exposed using a \#1/4 round bur under a surgical microscope (MC-M92; Seiler, St Louis, MO, USA) as described. ${ }^{7}$ Animals without infection served as negative controls. Four human dentoalveolar pathogens, Prevotella intermedia ATCC 25611, Streptococcus intermedius ATCC 27335, Fusobacterium nucleatum ATCC 25586 and Peptostreptococcus micros ATCC 33270 were grown on tryptic soy broth with yeast agar plates under anaerobic conditions $\left(80 \% \mathrm{~N}_{2}, 10 \% \mathrm{H}_{2}, 10 \% \mathrm{CO}_{2}\right)$, harvested and cultured in Mycoplasma liquid media (PPLO, Fisher Scientific, Pittsburgh, PA, USA). The cells were centrifuged and resuspended in pre-reduced anaerobically sterilized Ringer's solution (PRAS; Anaerobe Systems, Morgan Hill, CA, USA). Equal numbers of the four bacteria were mixed, placed into $2 \mathrm{~g}$ of methylcellulose per $\mathrm{mL} ; 4 \times 10^{8}$ total bacteria were transferred into the tooth pulp chamber and teeth were sealed with CAVIT.

\section{Antibodies and neutralization}

Goat anti-mouse interleukin (IL)- $1 \alpha$ and IL-1 $\beta$ affinity-purified polyclonal antibodies (IgG) were purchased from R\&D Systems, Minneapolis, MN, USA. Mice received $10 \mu \mathrm{g}$ antibodies subcutaneously on days $0,3,6,9$ and 12 relative to infection. Control mice received control goat IgG on the same schedule. On day 21 all mice were killed and samples prepared as described below.

\section{Estrogen (E2) supplementation}

Tablets of $17 \beta$-estradiol $(0.5 \mathrm{mg}, 21$ day slow release; Innovative Research of America, Sarasota, FL, USA) were surgically implanted subcutaneously in the backs of mice on day $0.17 \beta$-estradiol (Sigma, St Louis, MO, USA) was also used in cell cultures to determine effects on bacteria stimulated IL-1 production.

\section{Sample preparation}

Animals were killed by $\mathrm{CO}_{2}$ inhalation, and mandibles were removed and infrabony tissues from the right hemi-mandible isolated under a dissecting microscope. Tissues were weighed and placed into $1 \mathrm{~mL}$ of lysis buffer and ground using a sterile tissue homogenizer as described. ${ }^{8}$ The mixture was incubated at $4{ }^{\circ} \mathrm{C}$ for $1 \mathrm{~h}$, and the supernatant was collected after centrifugation and stored at $-80^{\circ} \mathrm{C}$ until assay. Left hemi-mandibles were fixed in $4 \%$ paraformaldehyde, decalcified, embedded in paraffin, sectioned at $7 \mu \mathrm{m}$ and stained with hematoxylin and eosin. The number of neutrophils and total inflammatory cells were counted under high power $(\times 200)$ within three predetermined fields including the right, center and left of the infrabony lesions, and means \pm standard deviation calculated.

\section{Macrophage cultures}

Unstimulated macrophages were collected by lavage with $3 \mathrm{~mL}$ cold phosphate-buffered saline (PBS) from the peritoneal cavity of normal $\mathrm{C} 57 \mathrm{Bl} / 6$ female mice, and cultured in medium containing estrogendepleted fetal bovine serum (FBS) (Invitrogen, Carlsbad, CA, USA) in the absence/presence of $17 \beta$-estradiol (estrogen, E2; Sigma, St Louis, $\mathrm{MO}$, USA) at $\log _{10}$ dilutions $\left(1 \times 10^{-4}-1 \mathrm{pg} \cdot \mathrm{mL}^{-1}\right)$ and/or E. coli lipopolysaccharide (LPS) (100 $\left.\mathrm{ng} \cdot \mathrm{mL}^{-1}\right)$ in triplicate. Supernatants were collected after $24 \mathrm{~h}$ and assayed for IL- $1 \alpha$ and IL- $1 \beta$ by enzymelinked immunosorbent assay (ELISA).

\section{Cytokine assays}

ELISAs for cytokines in tissue extracts employed commercially available kits for mouse IL-1 $\alpha$, IL-1 $\beta$, IL-4, IL-6, IL-10, IL-12, interferon $\gamma$ (IFN $\gamma$ ) and TNF $\alpha$ (all from BioSource International, Camarillo, CA, USA). All assays were carried out according to the manufacturer's instructions. Results were expressed as pg cytokine/mg infrabony tissue.

\section{Bacterial phagocytosis and killing assays}

Assays were performed to measure the phagocytosis and killing of Fusobacterium nucleatum (F. nucleatum) as a representative pathogen, as described ${ }^{9}$ using ex vivo leukocytes. In brief, whole blood $(1 \mathrm{~mL})$ was collected by cardiac puncture at killing on day 21 into a heparinized syringe, added to $9 \mathrm{~mL}$ dextran and allowed to sediment for $1 \mathrm{~h}$. The leukocyte rich buffy coat was collected, cells were counted, mixed with an equal volume of freshly grown $F$. nucleatum $\left(10^{6}\right.$ cells per $\mathrm{mL}$ in PRAS medium), and incubated at $37^{\circ} \mathrm{C}$ with rotation. Duplicate samples were taken at $0,10,20$ and $30 \mathrm{~min}$, and added to ice-cold PBS to stop the assay. The samples were centrifuged and the supernatants plated on pre-marked areas on blood agar plates (two cultures /sample/ time point) to assess the numbers of non-internalized bacteria. To measure internalized bacteria, the leukocyte pellet was washed in icecold PBS, homogenized with $20 \mu \mathrm{L}$ Saponin (Sigma, St Louis, MO, USA) in $1 \mathrm{~mL}$ ice-cold PBS, and the cell contents plated on blood agar plates. Plates were cultured for 3 days under anaerobic conditions, and bacterial colonies were counted under a dissecting microscope.

\section{Statistical analysis}

Student's $t$-test was used to analyze the effect of E2 and lipopolysaccharide (LPS) on IL- $1 \alpha$ and IL- $1 \beta$ production. One-way analysis of variance (ANOVA) with Tukey's standardized test was used for neutrophil and total inflammatory cell counts, animal and spleen weights, and the levels of cytokines. A mixed model repeated measures analysis of group/time effects was used to analyze phagocytosis and killing assays. $\chi^{2}$ with the Bonferroni correction was used for frequency of abscess formation.

\section{RESULTS}

Effect of systemic neutralization of IL-1 $\alpha$ and IL-1 $\beta$ on abscess formation and sepsis

We determined the effect of the functional inhibition of IL-1 $\alpha$ and/or IL-1 $\beta$ on the resistance of mice to disseminating infections, by blocking IL-1 isoforms with neutralizing antibodies. Mice were subjected to dentoalveolar infection with a mixture of four common human endodontic pathogens, and were treated subcutaneously with neutralizing antibodies against mouse IL- $1 \alpha$, IL- $1 \beta$, or both (antiIL- $1 \alpha / \beta$ ) on days $0,3,6,9$ and 12 relative to infection, or received unreactive goat IgG as a control. As seen in Table 1, both male and female mice treated with either anti-IL-1 $\alpha$ or anti-IL-1 $\beta$ alone as well as controls treated with unreactive IgG did not develop abscesses or sepsis. In contrast, most (6/8) male mice treated with the combination of anti-IL- $1 \alpha$ plus anti-IL-1 $\beta$ antibodies (anti-IL- $1 \alpha / \beta$ ) developed orofacial abscesses beginning 5-7 days after infection, pathognomonic for disseminating dentoalveolar infections (Figure 1a). Abscesses

Table 1 Frequency of dentoalveolar abscesses and sepsis in antiIL-1-treated mice

Treatment

\begin{tabular}{lccc} 
Sex & Anti-IL- $1 \alpha$ & Anti-IL-1 $\beta$ & Anti-IL-1a/ $\beta$ \\
\hline Male & $0 / 8$ & $0 / 8$ & $6 / 8^{*}$ \\
Female & $0 / 8$ & $0 / 8$ & $1 / 8$ \\
\hline
\end{tabular}

IL, interleukin.

${ }^{*} P<0.05$ vs females. 

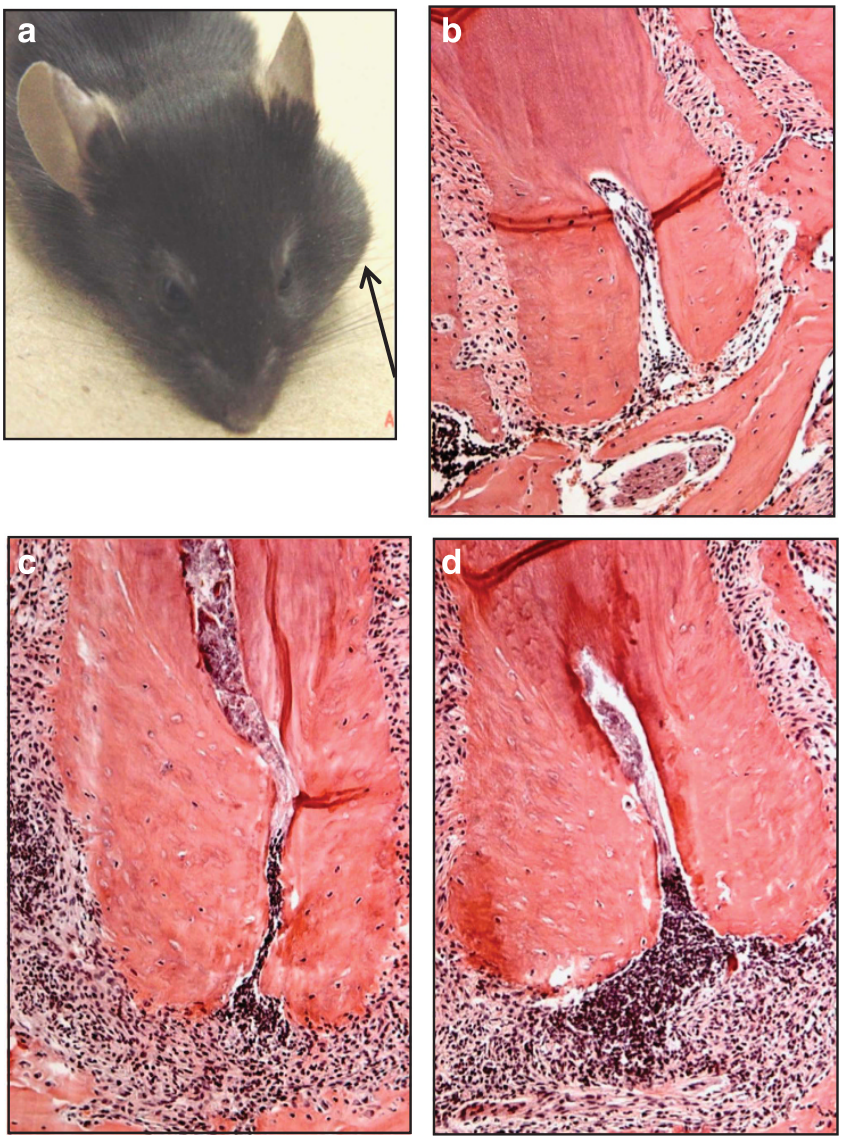

Figure 1 Pathology of infrabony lesions after dentoalveolar infection. (a) Male mouse subjected to infection and treatment with anti-IL-1 $\alpha / \beta$ neutralizing antibodies in vivo, demonstrating a large orofacial abscess (arrow). Histology of: (b) uninfected control; (c) infected dental pulp, mouse treated with unreactive IgG; (d) infected, anti-IL-1 $\alpha / \beta$ antibody. Note normal cellular detail, close apposition of bone to tooth in uninfected dental pulp in (b) indicating viable tissue, and absence of infiltrating inflammatory cells in the infrabony area surrounding the tooth. Cellular detail is lost in (c, d) indicative of dental pulp necrosis as a result of infection. The greatest number of infiltrating cells was present in lesions in mice that received antiIL- $1 \alpha / \beta$ antisera (panel d; see also Figure 2). Paraffin sections, hematoxylin and eosin staining; magnification $\times 200$. IgG, immunoglobulin G; IL, interleukin.

manifested as large swellings that extended into facial spaces. Affected animals also had reduced physical activity, loss of body weight and splenomegaly, all indicators of sepsis. In contrast only 1 of 8 female mice treated with the anti-IL- $1 \alpha / \beta$ combination developed a small abscess, but did not exhibit weight loss or splenomegaly, indicating a localized lesion. These data suggest that the functional absence of both IL-1 isoforms, which signal through the common IL-1RI, results in an inability of male mice to localize dentoalveolar infections, leading to abscesses and sepsis.

\section{Cell Infiltration in anti-IL-1-treated mice}

Mandibles from each animal were processed for histology (Figure 1, panels $\mathbf{b}-\mathbf{d}$ ), and infiltrating neutrophils and total inflammatory cells were quantified (Figure 2). Animals receiving either antibody alone showed slightly reduced cell infiltration (not significant (NS) vs controls), whereas those treated with the anti-IL- $1 \alpha / \beta$ combination had the greatest number of infiltrating neutrophils and total

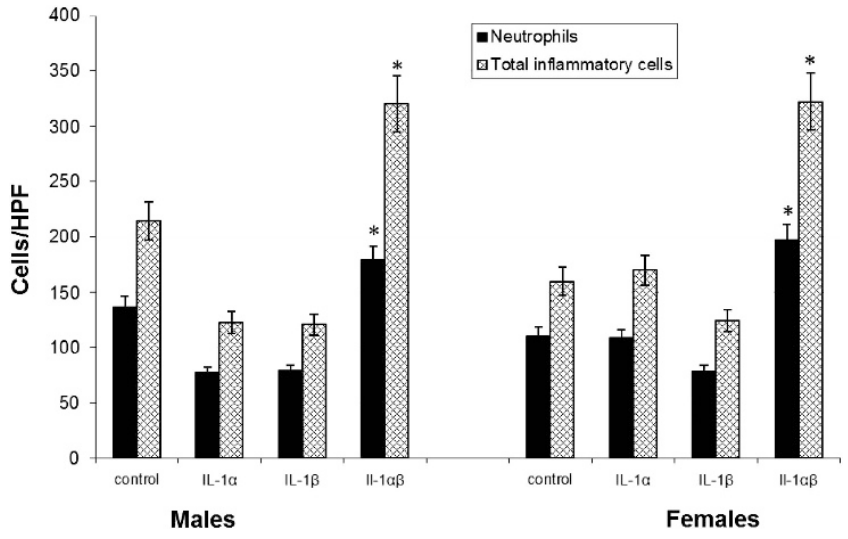

Figure 2 Infrabony inflammatory cell infiltration in anti-IL-1-treated male and female mice subjected to dentoalveolar infection. The mean number of total inflammatory cells and neutrophils was determined in three highpowered fields in each treatment group $(n=8)$. A significant increase in infiltrating neutrophils and other inflammatory cells occurred in mice treated with anti-IL-1 $\alpha / \beta$ antisera vs all other groups. There were no differences between males and females. Vertical bars: standard deviation ${ }^{*} P=0.05$ by ANOVA. ANOVA, one-way analysis of variance; HPF, high-powered field; IL, interleukin.

inflammatory cells after 21 days (Figure 2, $P<0.03$ ). This indicates that neutrophil migration was not affected by anti-IL- $1 \alpha / \beta$ blockade, suggesting that another function may have been compromised leading to a failure to localize infections.

\section{Cytokine expression in infrabony lesions}

The levels of cytokines in infrabony lesions were evaluated by ELISA on day 21 post-infection (Figure 3). Both male and female mice treated with the combination of anti-IL- $1 \alpha / \beta$ antibodies showed a significant suppression of IL-6, IL-12 and IFN $\gamma$ compared with controls and to mice treated with either antibody alone, indicating that IL-1RI signaling positively regulates all three mediators. In contrast, IL-10, IL- $1 \alpha$, IL- $1 \beta$ and tumour necrosis factor $\alpha(\mathrm{TNF} \alpha)$ showed no differences among treatment groups. As shown in Figure 4, tissue levels of IFN $\gamma$ were significantly lower in males than in females, and IL-12 and IL-6 trended lower but were not significant. Taken together these findings suggest the induction of a more predominant anti-inflammatory periapical environment in males $v s$ females.

\section{Effect of estrogen on infection dissemination}

The increased susceptibility of males $v s$ females to infection dissemination following IL-1 blockade suggested that sex-related factors, in particular estrogen, could be responsible for this difference. To determine the role of estrogen, female mice were OVX or treated by sham surgery as a control (SHAM). OVX females were further separated into two groups, one of which received a slow release estrogen implant subcutaneously that provided estrogen over 21 days, and the other without supplementation. The animals were then either given injections of anti-IL- $\alpha / \beta$ antibody or unreactive $\operatorname{IgG}$ as a control as above.

As seen in Table 2, OVX female mice that also received antiIL- $1 \alpha / \beta$ antibodies developed a high frequency of abscess 

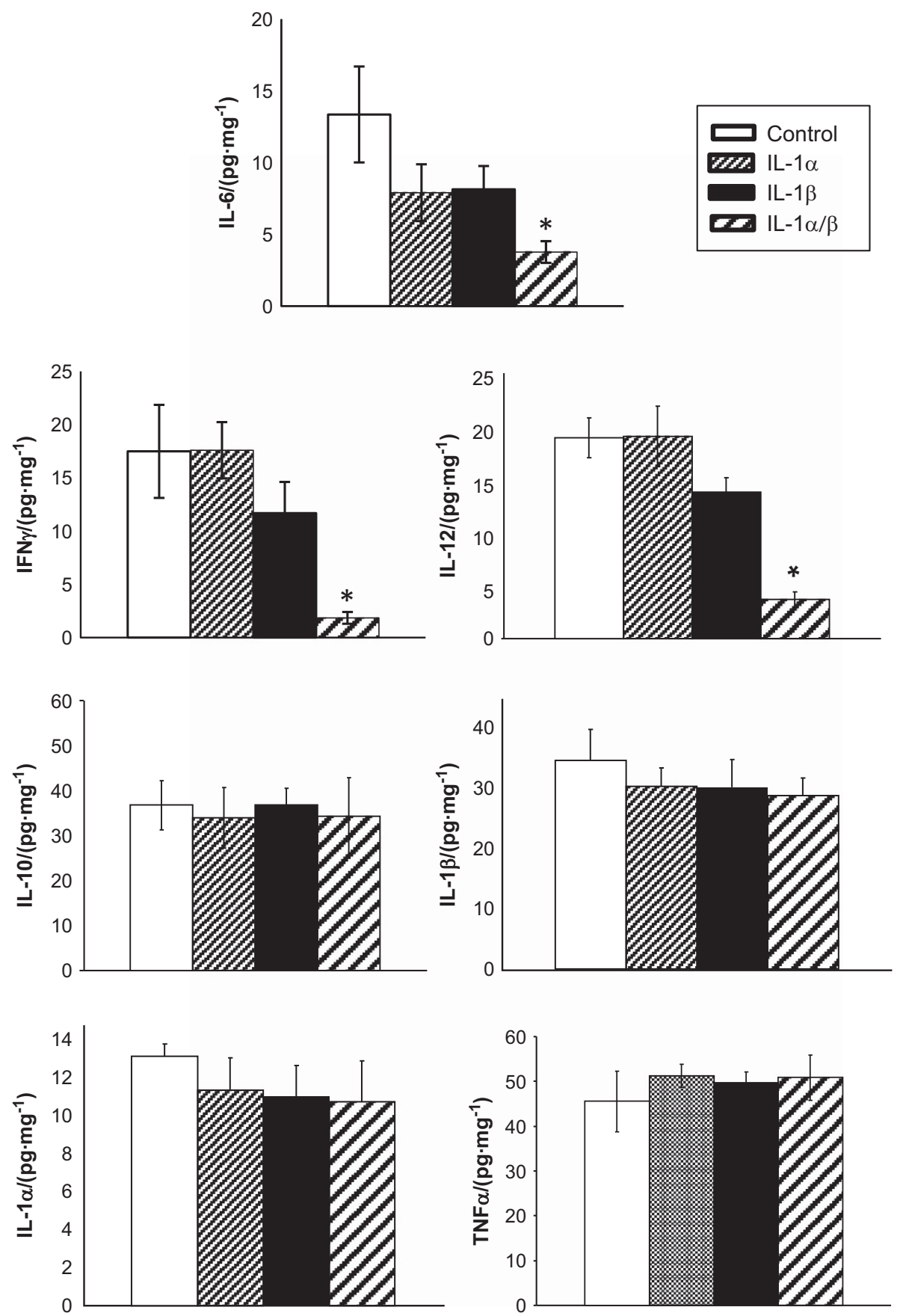

Figure 3 Effect of anti-IL-1 neutralizing antibodies on cytokine expression in infrabony lesions; pooled data from male and female mice. Significant reductions were seen in tissue levels of IL-12, IFN $\gamma$ and IL-6 in mice treated with anti-IL-1 $\alpha / \beta$ antibodies; all other cytokines were unchanged ( $n=16$ animals/group). Bars and vertical lines: means \pm standard deviation ${ }^{*} P<0.01$ vs control IgG by ANOVA. ANOVA, one-way analysis of variance; IFN $\gamma$, interferon- $\gamma$; IL, interleukin; TNF $\alpha$, tumour necrosis factor $\alpha$.

development (7/10) and signs of infection dissemination including weight loss (Figure 5a, $P<0.04$ ) and splenomegaly compared with controls (Figure 5b, $P<0.04$ ). Infection dissemination was nearly completely reversed by supplementation with estrogen $(17 \beta$ estradiol; Table 2) as were weight loss and splenomegaly. None of the other groups developed significant numbers of abscesses, again confirming the role of anti-IL- $1 \alpha / \beta$ blockade in this outcome.
Ex vivo phagocytosis and killing studies

As seen above (Figure 2), the increased numbers of infiltrating leukocytes in infrabony lesions of anti-IL- $1 \alpha / \beta$-treated animals indicated that cell migration was not affected, and that infection dissemination may be explained by reduced phagocytic cell bactericidal activity. To investigate this possibility, the phagocytic and bactericidal activities of peripheral blood leukocytes isolated from animals in the preceding OVX experiment were tested 

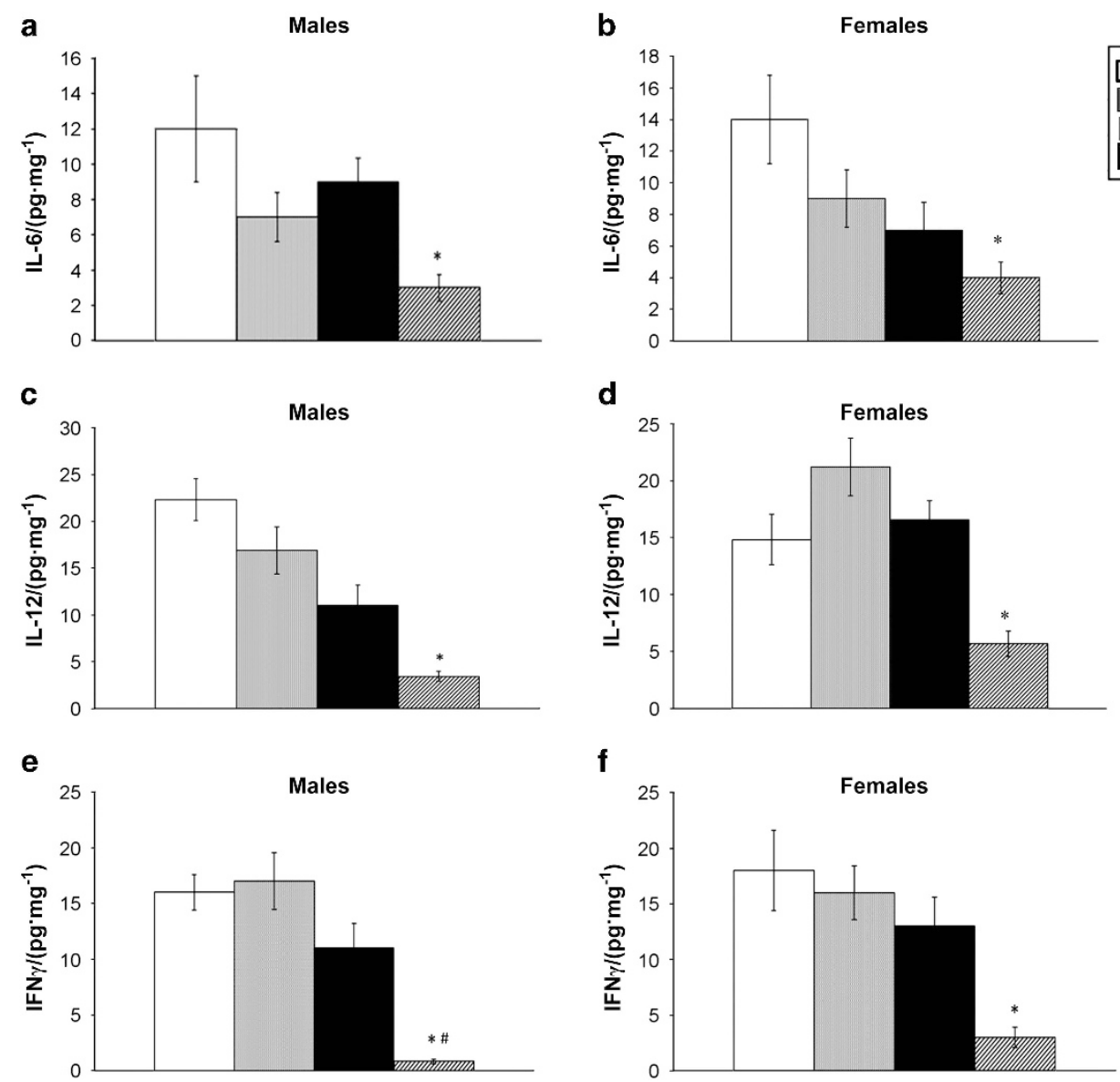

Figure 4 Effect of anti-IL-1 antibodies on cytokine expression in infrabony lesions in male vs female mice. Panels: infrabony lesion tissue levels of: (a) IL-6, males; (b) IL-6, females; (c) IL-12, males; (d) IL-12, females; (e) IFN $\gamma$, males; (f) IFN $\gamma$, females. ${ }^{*} P<0.01$ vs control IgG treatment by ANOVA. A significantly greater reduction in IFN $\gamma$ occurred in males vs females treated with anti-IL-1 $\alpha / \beta$ antibodies. ${ }^{*} P<0.05$ vs females by $t$-test. $n=8$ animals/group; bars and vertical lines: means \pm standard deviation ANOVA, one-way analysis of variance; IFN $\gamma$, interferon- $\gamma$; IgG, immunoglobulin G; IL, interleukin; TNF $\alpha$, tumour necrosis factor $\alpha$.

Table 2 Effect of estrogen modulation on abscesses and sepsis in anti-IL-1-treated female mice

\begin{tabular}{lcc}
\hline Treatment & Control lgG & Anti-IL-1 $\alpha / \beta$ \\
\hline Sham OVX (control) & $0 / 11^{*}$ & $1 / 11$ \\
OVX & $2 / 11$ & $7 / 10$ \\
OVX+E2 implant & $0 / 11$ & $2 / 11^{\dagger}$
\end{tabular}

IgG, immunoglobulin G; IL, interleukin; OVX, ovariectomy.

${ }^{*}$ Frequency of abscesses/sepsis.

$\uparrow P<0.01$ by $\chi^{2}$.

using F. nucleatum as a model pathogen. As seen in Figure 6a, blood leukocytes isolated from OVX mice that received antiIL- $1 \alpha / \beta$ had the lowest phagocytic activity (solid squares, highest number of non-phagocytosed F. nucleatum) at all times tested. This effect was reversed in leukocytes from animals subjected to OVX and treated with anti-IL- $1 \alpha / \beta$ but also given estrogen supplementation $(P<0.004)$. The latter mice as well as leukocytes from OVX+E2 treated mice had higher phagocytic activity that approached that of the negative control (sham OVX, no anti-IL- $1 \alpha$ / $\beta)$. A similar result was obtained when the killing of $F$. nucleatum was determined (Figure 6b). The poorest killing of internalized bacteria was observed in the anti-IL- $\alpha / \beta+\mathrm{OVX}$ group $(P<0.004)$; killing was increased and approached control levels with estrogen supplementation.

\section{IL-1 production by macrophages in response to LPS and estrogen} To determine if estrogen upregulates IL-1 as a possible mechanism for increased protection against disseminating infections, we assessed the effect of $17 \beta$-estradiol on the production of IL- 1 by macrophages. Unstimulated macrophages were isolated from the peritoneal cavities of female C57BL6 mice, and were cultured in estrogen-free medium in the presence/absence of LPS and estrogen. As expected, LPS stimulated both IL- $1 \alpha$ and IL- $1 \beta$ expression (Figure 7). However, estrogen alone also increased production of both IL- $1 \alpha$ and IL- $1 \beta$ in a dose-dependent manner, even at very low concentrations $\left(0.01 \mu \mathrm{g} \cdot \mathrm{mL}^{-1}\right)$. When cells were stimulated with the combination of LPS and estrogen, an additive rather than a synergistic response was observed. These data suggest that females, by the virtue of their estrogen production, may be relatively resistant to dentoalveolar infection dissemination because they produce higher constitutive levels of IL-1, resulting in greater neutrophil priming than males. 


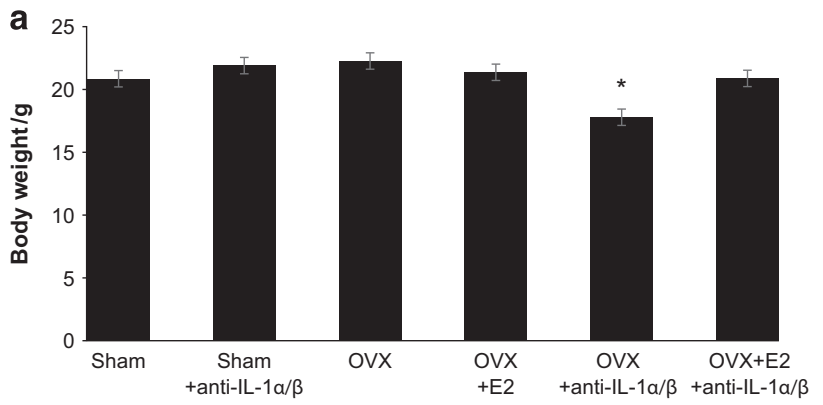

b

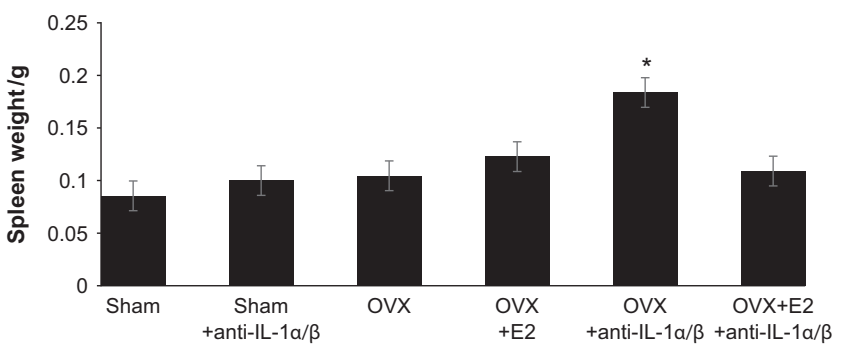

Figure 5 Effect of anti-IL-1 $\alpha / \beta$ antibodies and estrogen modulation on body weight and splenomegaly. (a) Body weight was significantly reduced and (b) spleens were enlarged in mice lacking estrogen that also received anti-IL- $1 \alpha / \beta$ antibodies $(n=11$ animals/group). Bars and vertical lines: mean \pm standard deviation ${ }^{*} P<0.05$ vs controls by ANOVA. ANOVA, one-way analysis of variance; IL, interleukin.
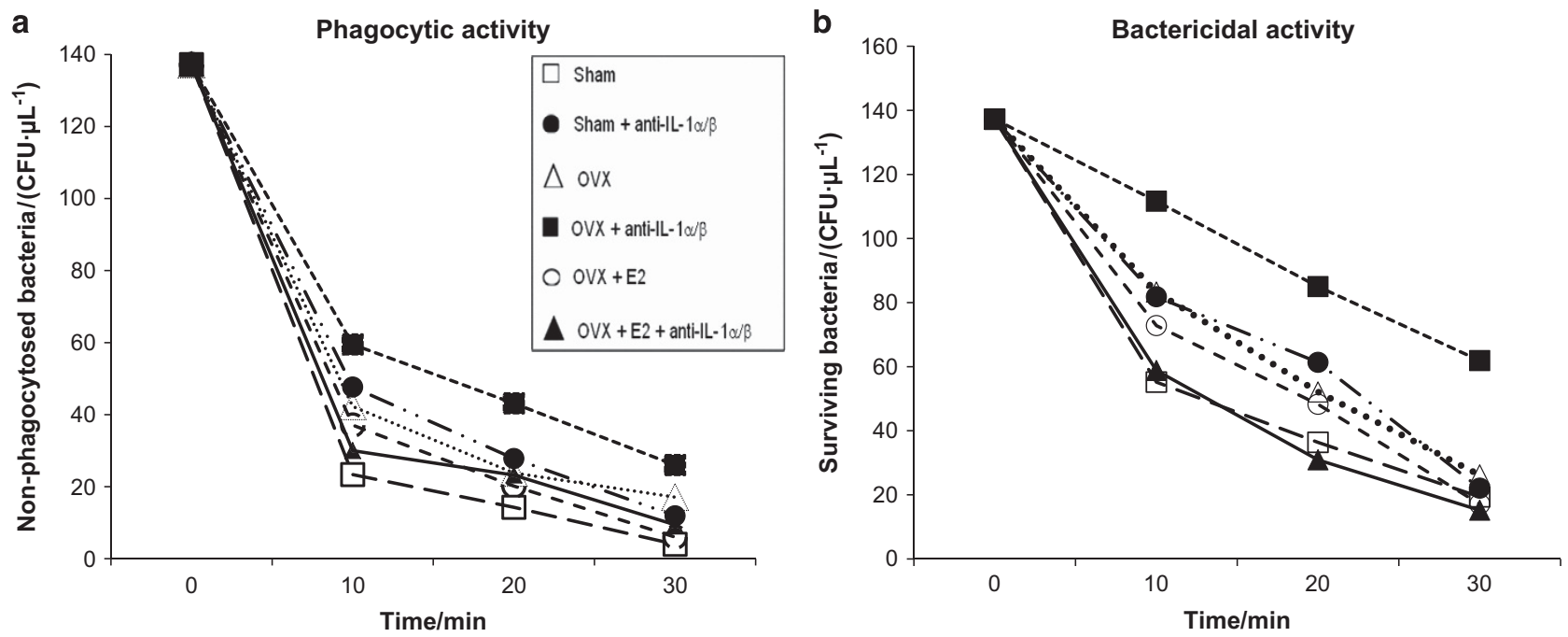

Figure 6 Effect of anti-IL-1 antisera and OVX on phagocytosis and killing of bacteria by peripheral blood neutrophils. Panels: (a) more bacteria remained non-internalized, and (b) fewer internalized bacteria were killed in the OVX+anti-IL-1 $\alpha / \beta$ treated group vs all other groups $(n=11) .{ }^{*} P<0.004$, multiple regression analysis. IL, interleukin; OVX, ovariectomy.
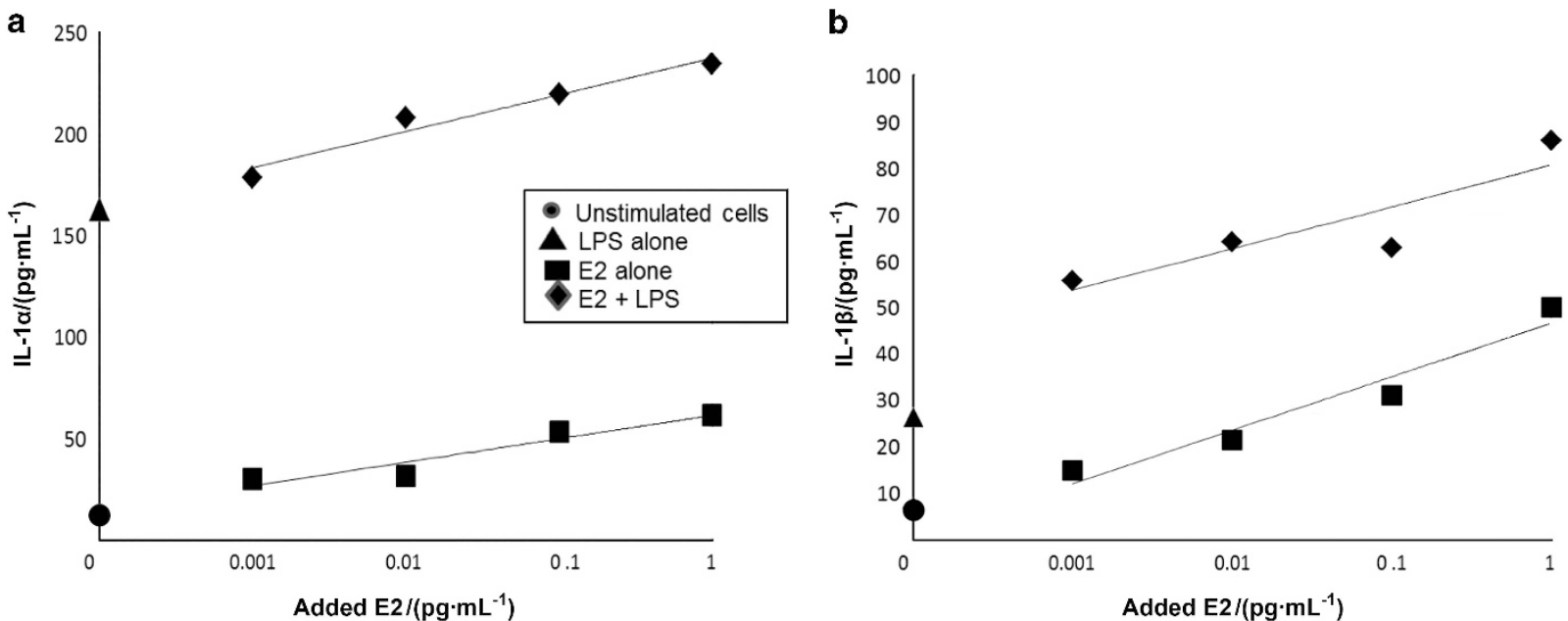

Figure 7 Effect of estrogen (E2) and LPS on IL-1 $\alpha$ and IL-1 $\beta$ production by macrophages in vitro. The effect of E2 and LPS on both IL-1 isoforms was additive ( ${ }^{*} P<0.05, t$-test). E2, estrogen; IL, interleukin. 


\section{DISCUSSION}

Spreading dentoalveolar infections constitute a significant and growing public health problem, and in severe cases are life-threatening. In the present study, we undertook to further characterize the host immune factors that protect against disseminating dentoalveolar infections in a novel mouse model. Our results indicate that the priming and activation of neutrophils at least in part by estrogen, possibly via increased expression of IL-1, comprises a critical host defense mechanism.

There is compelling evidence from human epidemiological studies that females are more resistant to infectious challenges and sepsis than males, whereas females are more susceptible to autoimmune diseases. ${ }^{10-13}$ Post-trauma mortality from sepsis was also higher in males younger than 50 years of age, a difference that disappeared in patients older than 50 years, suggestive of menopausal changes in females. ${ }^{14}$ Along these lines pre-pubertal females and males had similar sepsis mortality, but this was reduced by $\sim 50 \%$ after puberty in females. ${ }^{15}$

Circulating estrogen levels are most closely correlated with infection resistance, and estrogen has been shown to regulate the expression of a broad array of sexually dimorphic autosomal genes in human peripheral blood cells. ${ }^{16}$ Female-biased gene ontology categories were highly enriched for various immune system functions, including TLR3 and TLR4 pathways (poly I:C and LPS responses), genes linked to the autoimmune diseases, as well as genes regulated by estrogen and LPS. Significant subcategories included responses to cytokine and type 1 interferon stimulation, and lymphocyte differentiation. These functional expression patterns are also reflected in sexually dimorphic immune responses in mice, ${ }^{17}$ leading to increased humoral, ${ }^{18} \mathrm{~T}$ cell ${ }^{19}$ and innate immune responses. ${ }^{20}$ As noted above, B-cell-deficient mice are susceptible to dentoalveolar sepsis, but are largely protected by the passive transfer of anti-bacterial IgG antibodies. As C5 complementdeficient mice were not susceptible, it is likely that opsonization of bacteria to enhance phagocytosis by neutrophils and macrophages is a key protective mechanism. ${ }^{3-4} \mathrm{CD} 4+\mathrm{T}$ cells may also participate, principally by providing 'help' for B cells. ${ }^{19}$

In contrast male hormones are reported to be immunosuppressive, ${ }^{21}$ and treatment with the androgen receptor antagonist flutamide increased cytokine responses in male mice with trauma and sepsis, and improved survival. ${ }^{22-23}$ Treatment with the estrogen receptor-beta agonist WAY-202196 improved survival, preserved intestinal epithelial integrity, and significantly reduced systemic bacteremia and peritoneal interleukin- 6 and tumor necrosis factor levels in the same model, and provided a comparable level of protection in both male and female animals ${ }^{24}$ Taken together these studies indicate that although estrogen may protect primarily by enhancing neutrophil priming and bactericidal activity, and indirectly through stimulation of antibody responses, other estrogen-stimulated mechanisms could also be operative.

Sex differences in disseminating infections of dentoalveolar origin have been less clear. More males than females were hospitalized with severe dentoalveolar infections in several studies, ${ }^{25-26}$ whereas equal frequencies were reported in others. ${ }^{27-28} \mathrm{In}$ a recent large retrospective analysis of more than 60000 cases from 2000-2008, more females than males were hospitalized for severe periapical abscesses. ${ }^{29}$ However of 66 deaths in this cohort, 42 were males and 24 were females $(P<0.02 ; \mathrm{V}$. Allareddy, personal communication). A similar mortality bias was observed in a study of more than four million emergency room visits from 2008 to 2010 for conditions including pulpal/ periapical lesions, oral cellulitis or abscess. ${ }^{30}$ Of 101 deaths in this series, 58 were males and 43 were females (V. Allareddy, personal communication). It thus appears that sepsis of dentoalveolar origin also has more severe effects on males than females, similar to other body sites, and consistent with the findings in the present study. A similar gender-biased mortality as observed in the present study was also reported using IL-1 and TNF receptor knockout mice, ${ }^{31}$ albeit the cellular and molecular mechanisms underlying resistance in females were not determined.

A question remains whether the effects of IL-1 on phagocytic leukocytes is direct, or indirect via induction of other proinflammatory mediators such as IL-12 and IFN $\gamma$, both of which have been reported to protect against polymicrobial sepsis. ${ }^{32}$ IL-1 can directly prime neutrophils and monocytes for enhanced anti-microbial activity. ${ }^{33-35}$ However in our studies, IL- $1 \alpha$, IL-1 $\beta$ and TNF $\alpha$ levels were unchanged following anti-IL-1 blockade (Figure 3), suggesting an indirect effect. In contrast, periapical lesion levels of IL-6, IL-12 and IFN $\gamma$ were significantly reduced and IL-10 was unchanged, suggestive of the induction of a predominantly anti-inflammatory local immune response. Of note, IFN $\gamma$ was significantly lower in males $v s$ females and IL-12 trended lower, suggesting that inhibition of these cytokines may have a critical role in male susceptibility. Further studies are required to resolve this issue.

This local anti-inflammatory mileau is furthermore consistent with a predominance of N2 neutrophil and M2 macrophage infiltration. ${ }^{36}$ The recent description of distinct neutrophil phenotypic/functional subsets $^{37}$ may be relevant. First described in the context of solid tumors similar to polarized macrophages, neutrophils may exhibit either a pro-inflammatory (N1) or anti-inflammatory/immunosuppressive (N2) functional profile, with the production of immunosuppressive cytokines including IL-10, and TGF $3 .^{38-41}$ For example in sepsis following burn injury, circulating IL-10 vs IL-12 is elevated, and the numbers of $\mathrm{N} 2$ that express $\mathrm{IL}-10^{\text {hi }}$ and $\mathrm{IL}-12^{\text {lo }}$ are increased. ${ }^{42-43}$ Sepsis is dramatically reduced by polarization toward the N1 phenotype with flagellin, a TLR5 agonist. ${ }^{43} \mathrm{~N} 1$ cells are similarly protective against $S$. aureus infections 44 and in inflammatory brain injury. ${ }^{45}$ Additional studies are needed to define the neutrophil subset associated with protection $v$ s susceptibility in this model, along with a possible role for other cell types. Finally, the ability to modulate infection resistance using sex hormone modulation should be further explored to better prevent hese potentially lethal infections.

\section{ACKNOWLEDGEMENTS}

We thank Drs H Sasaki and K Balto for assistance and advice, Dr R Kent for statistical analysis, Dr V Allareddy for providing unpublished data, Ms. Justine Dobeck for histology and Mr S Yoganathan for expert animal care. This work supported by grant DE-11664 (PS) from the National Institute of Dental and Craniofacial Research/National Institutes of Health (NIDCR/NIH), and a grant from the American Association of Endodontists (HY).

1 Lypka M, Hammoudeh J. Dentoalveolar infections. Oral Maxillofac Surg Clin North Am 2011; 23(3): 415-424.

2 Walsh LJ. Serious complications of endodontic infections: some cautionary tales. Aust Dent J 1997; 42(3): 156-159.

3 Teles R, Wang CY, Stashenko P. Increased susceptibility of RAG-2 SCID mice to dissemination of endodontic infections. Infect Immun 1997; 65(9): 3781-3787.

4 Hou L, Sasakj H, Stashenko P. B-Cell deficiency predisposes mice to disseminating anaerobic infections: protection by passive antibody transfer. Infect Immun 2000; 68 (10): 5645-5651.

5 Kawashima N, Niederman R, Hynes RO et al. Infection-stimulated infraosseus inflammation and bone destruction is increased in P-/E-selectin knockout mice. Immunology 1999; 97(1): 117-123.

6 Stashenko P, Wang CY, Riley E et al. Reduction of infection-stimulated periapical bone resorption by the biological response modifier PGG glucan. J Dent Res 1995; 74(1): 323-330. 
7 Stashenko P, Gonçalves RB, Lipkin B et al. Th1 immune response promotes severe bone resorption caused by Porphyromonas gingivalis. Am J Pathol 2007; 170(1): 203-213.

8 AlShwaimi $\mathrm{E}$, Berggreen $\mathrm{E}$, Furusho $\mathrm{H}$ et al. IL-17 receptor $\mathrm{A}$ signaling is protective in infection-stimulated periapical bone destruction. J Immunol 2013; 191(4): 1785-1791.

9 Herrera BS, Hasturk H, Kantarci A et al. Impact of resolvin E1 on murine neutrophil phagocytosis in type 2 diabetes. Infect Immun 2015; 83(2): 792-801.

10 Schoeneberg C, Kauther MD, Hussmann B et al. Gender-specific differences in severely injured patients between 2002 and 2011: data analysis with matched-pair analysis. Crit Care 2013; 17(6): R277.

11 Angele MK, Pratschke S, Hubbard WJ et al. Gender differences in sepsis: cardiovascular and immunological aspects. Virulence 2014; 5(1): 12-19.

12 Bouza C, López-Cuadrado T, Saz-Parkinson Z et al. Epidemiology and recent trends of severe sepsis in Spain: a nationwide population-based analysis (2006-2011). BMC Infect Dis 2014; 14: 3863.

13 Kisat M, Villegas CV, Onguti S et al. Predictors of sepsis in moderately severely injured patients: an analysis of the National Trauma Data Bank. Surg Infect : Larchmt 2013; 14(1): 62-68

14 Mahmood K, Eldeirawi K, Wahidi MM. Association of gender with outcomes in critically ill patients. Crit Care 2012; 16(3): R92.

15 Ghuman AK, Newth CJ, Khemani RG. Impact of gender on sepsis mortality and severity of illness for prepubertal and postpubertal children. J Pediatr 2013; 163(3): 835.e1-840.e1.

16 Jansen R, Batista S, Brooks Al et al. Sex differences in the human peripheral blood transcriptome. BMC Genomics 2014; 15: 33.

17 Yang $X$, Schadt EE, Wang S et al. Tissue-specific expression and regulation of sexually dimorphic genes in mice. Genome Res 2006; 16(8): 995-1004.

18 Sakiani S, Olsen NJ, Kovacs WJ. Gonadal steroids and humoral immunity. Nat Rev Endocrinol 2013; 9(1): 56-62.

19 Michalek RD, Gerriets VA, Nichols AG et al. Estrogen-related receptor- $\alpha$ is a metabolic regulator of effector T-cell activation and differentiation. Proc Natl Acad Sci USA 2011; 108(45): 18348-18353.

20 Kovats S. Estrogen receptors regulate innate immune cells and signaling pathways. Cell Immunol 2015; 294(2): 63-69.

21 Trigunaite A, Dimo J, Jørgensen TN. Suppressive effects of androgens on the immune system. Cell Immunol 2015; 294(2): 87-94.

22 Angele MK, Wichmann MW, Ayala A et al. Testosterone receptor blockade after hemorrhage in males. Restoration of the depressed immune functions and improved survival following subsequent sepsis. Arch Surg 1997; 132(11): 1207-1214.

23 Ongaro L, Castrogiovanni D, Giovambattista A et al. Enhanced proinflammatory cytokine response to bacterial lipopolysaccharide in the adult male rat after either neonatal or prepubertal ablation of biological testosterone activity. Neuroimmunomodulation 2011; 18(4): 254-260.

24 Cristofaro PA, Opal SM, Palardy JE et al. WAY-202196, a selective estrogen receptorbeta agonist, protects against death in experimental septic shock. Crit Care Med 2006; 34(8): 2188-2193.

25 Storoe W, Haug RH, Lillich TT. The changing face of odontogenic infections. J Oral Maxillofac Surg 2001; 59(7): 739-748.

26 Wang J, Ahani A, Pogrel MA. A five-year retrospective study of odontogenic maxiIlofacial infections in a large urban public hospital. Int J Oral Maxillofac Surg 2005; 34(6): 646-649.

27 Sánchez R, Mirada E, Arias J et al. Severe odontogenic infections: epidemiological, microbiological and therapeutic factors. Med Oral Patol Oral Cir Bucal 2011; 16(5): e670-e676.

28 Kudiyirickal MG, Hollinshead F. Clinical profile of orofacial infections: an experience from two primary care dental practices. Med Oral Patol Oral Cir Bucal 2012; 17(4): e533-e537.

29 Shah AC, Leong KK, Lee MK et al. Outcomes of hospitalizations attributed to periapical abscess from 2000 to 2008: a longitudinal trend analysis. J Endod 2013; 39(9): 1104-1110.
30 Allareddy V, Rampa S, Lee MK et al. Hospital-based emergency department visits involving dental conditions: profile and predictors of poor outcomes and resource utilization. J Am Dent Assoc 2014; 145(4): 331-337.

31 Graves DT, Chen CP, Douville C et al. Interleukin- 1 receptor signaling rather than that of tumor necrosis factor is critical in protecting the host from the severe consequences of a polymicrobe anaerobic infection. Infect Immun 2000; 68(8): 4746-4751.

32 Moreno SE, Alves-Filho JC, Alfaya TM et al. IL-12, but not IL-18, is critical to neutrophil activation and resistance to polymicrobial sepsis induced by cecal ligation and puncture. J Immunol 2006; 177(5): 3218-3224.

33 Yagisawa M, Yuo A, Kitagawa $\mathrm{S}$ et al. Stimulation and priming of human neutrophils by IL-1 alpha and IL-1 beta: complete inhibition by IL-1 receptor antagonist and no interaction with other cytokines. Exp Hematol 1995; 23(7): 603-608.

34 Simbirtsev A, Variouchina E, Konusova $V$ et al. Local administration of interleukin1 beta for the treatment of lung abscesses induces neutrophil activation and changes in proinflammation cytokine production. Eur Cytokine Netw 2001; 12(3): 420-429.

35 Wright HL, Thomas HB, Moots RJ et al. RNA-seq reveals activation of both common and cytokine-specific pathways following neutrophil priming. PLoS One 2013; 8(3): e58598.

36 Fridlender ZG, Sun J, Kim S et al. Albelda SM. Polarization of tumor-ssociated neutrophil phenotype by TGF-beta: "N1" versus "N2" TAN. Cancer Cell 2009; 16(3): 183-194.

37 Beyrau M, Bodkin JV, Nourshargh S. Neutrophil heterogeneity in health and disease: a revitalized avenue in inflammation and immunity. Open Biol 2012; 2(11): 120134.

38 Gabrilovich DI, Ostrand-Rosenberg S, Bronte V. Coordinated regulation of myeloid cells by tumours. Nat Rev Immunol 2012; 12(4): 253-268.

39 Magalhaes MA, Glogauer JE, Glogauer M. Neutrophils and oral squamous cell carcinoma: lessons learned and future directions. J Leukoc Biol 2014; 96(5): 695-702.

40 Sionov RV, Fridlender ZG, Granot Z. The multifaceted roles neutrophils play in the tumor microenvironment. Cancer Microenviron 2015; 8(3): 125-158.

41 Galdiero MR, Garlanda C, Jaillon S et al. Tumor associated macrophages and neutrophils in tumor progression. J Cell Physiol 2013; 228(7): 1404-1412.

42 Kasten KR, Muenzer JT, Caldwell CC. Neutrophils are significant producers of IL-10 during sepsis. Biochem Biophys Res Commun 2010; 393(1): 28-31.

43 Neely CJ, Kartchner LB, Mendoza AE et al. Flagellin treatment prevents increased susceptibility to systemic bacterial infection after injury by inhibiting antiinflammatory IL-10+ IL-12- neutrophil polarization. PLoS One 2014; 9(1): e85623.

44 Pozzi C, Lofano G, Mancini F et al. Phagocyte subsets and lymphocyte clonal deletion behind ineffective immune response to Staphylococcus aureus. FEMS Microbiol Rev 2015; 39(5): 750-763.

45 Cuartero MI, Ballesteros I, Moraga A et al. N2 neutrophils, novel players in brain inflammation after stroke: modulation by the PPAR $\gamma$ agonist rosiglitazone. Stroke 2013; 44(12): 3498-3508.

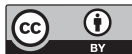

This work is licensed under a Creative Commons Attribution 4.0 International License. The images or other third party material in this article are included in the article's Creative Commons license, unless indicated otherwise in the credit line; if the material is not included under the Creative Commons license, users will need to obtain permission from the license holder to reproduce the material. To view a copy of this license, visit http://creativecommons.org/licenses/by/4.0/

(C) The Author(s) 2017 